\title{
Direct oral anticoagulants and their clinical management
}

\begin{abstract}
Thrombotic disorders are treated mostly with Heparin and Warfarin in cases requiring anticoagulation drugs. Due to limitations to these drugs including risk of bleeding and need for regular laboratory monitoring several Direct oral anticoagulants (DOACs) have been developed and shown to have more advantages than Warfarin. Nevertheless, these drugs are limited to use in some circumstances. As other anticoagulants, these drugs need to be managed and controlled to cope their over activities. Subsequently, many antidotes have been developed to reverse these DOACs. However, these antidotes are still understudies and need to be fully approved. The assessment of DOACs is developing and several drug-specific calibrators have been developed to measure DOACs activity in plasma.
\end{abstract}

Keywords: vitamin $\mathrm{K}$ antagonist, coronary artery, atrial fibrillation, heparin, warfarin
Volume 5 Issue 5 - 2017

\author{
Gasim Dobie, Cindy J Omalley, Daniel Sze, \\ Denise E Jackson \\ RMIT University, Australia
}

\begin{abstract}
Correspondence: Denise E Jackson, BAppSc (MLS), FAIMS, PhD, FFSc, Discipline Leader of Laboratory Medicine, Head of Thrombosis and Vascular Diseases Laboratory, School of Health and Biomedical Sciences, RMIT University, PO Box 7I, Bundoora.Victoria. 3083, Australia, Fax 613 9925-7063, Tel 613 9925-7392, Email denise.jackson@rmit.edu.au
\end{abstract}

Received: November 09, 2017 | Published: December 01,
Abbreviations: DOACs, direct oral anticoagulants; DVT, deep venous thrombosis; PE, pulmonary embolus; PBS, pharmaceutical benefits scheme; PD, pharmacodynamic; PK, pharmacokinetics; TGA, therapeutic good administration; PCC, prothrombin complex concentrate; PT, prothrombin time; aPTT, activated atrial thromboplastin time; FDA, food and drug administration

\section{Introduction}

Heparin and warfarin (Vitamin K antagonist) are the most often prescribed anticoagulant drugs used to treat patients with thrombotic disorders. Venous thromboembolism and atrial occlusion (coronary artery blockage) can be treated with heparin whereas atrial fibrillation and mechanical heart valve are treated with warfarin. Warfarin is still the backbone for long term treatment while the heparin is best used for short term therapy. Although these drugs are highly effective, they have recognized limitations. Both drugs are related with the risk of bleeding. ${ }^{1}$ The most common drug-related complications associated with heparin are osteopenia and thrombocytopenia. ${ }^{2}$ Warfarin needs intensive laboratory monitoring; its doses are variable and can interact with other drugs.

New non-vitamin $\mathrm{K}$ oral anticoagulants have been developed including Dabigatran (Pradaxa), Rivaroxaban (Xarelto) and Apixaban (Eliquis). These have been listed on the Pharmaceutical Benefits Scheme (PBS) in $2012^{3}$ and currently approved in Australia. ${ }^{2}$ Edoxaban (Savaysa) is also another DOAC, has been developed to inhibit factor Xa. These non-vitamin $\mathrm{K}$ antagonist drugs are approved as an alternative warfarin in treating and preventing some thrombotic indications such as thromboembolism in non-valvular atrial fibrillation, ${ }^{3}$ deep venous thrombosis (DVT) and pulmonary embolus $(\mathrm{PE}){ }^{2}$ They are used in fixed-dosing with few drugs interactions and do not need laboratory monitoring. ${ }^{4}$ These drugs block only the activity of one single factor (Figure 1A) which is different to vitamin $\mathrm{K}$ antagonists (Figure $1 \mathrm{~B}$ ) that prevent the post-translational modification of Vit $\mathrm{K}$ dependent factors (factors II, VII, IX, and $\mathrm{X}$ ). Apixaban and Rivaroxaban are direct reversible antagonists of activated factor $\mathrm{X}$ whereas Dabigatran is a direct reversible inhibitor of activated factor (IIa) thrombin. The use of DOACs is increasing while the rate of warfarin use is decreasing as shown in a retrospective observational study conducted by Pratt $\mathrm{N}$ and his research team Table 1.5
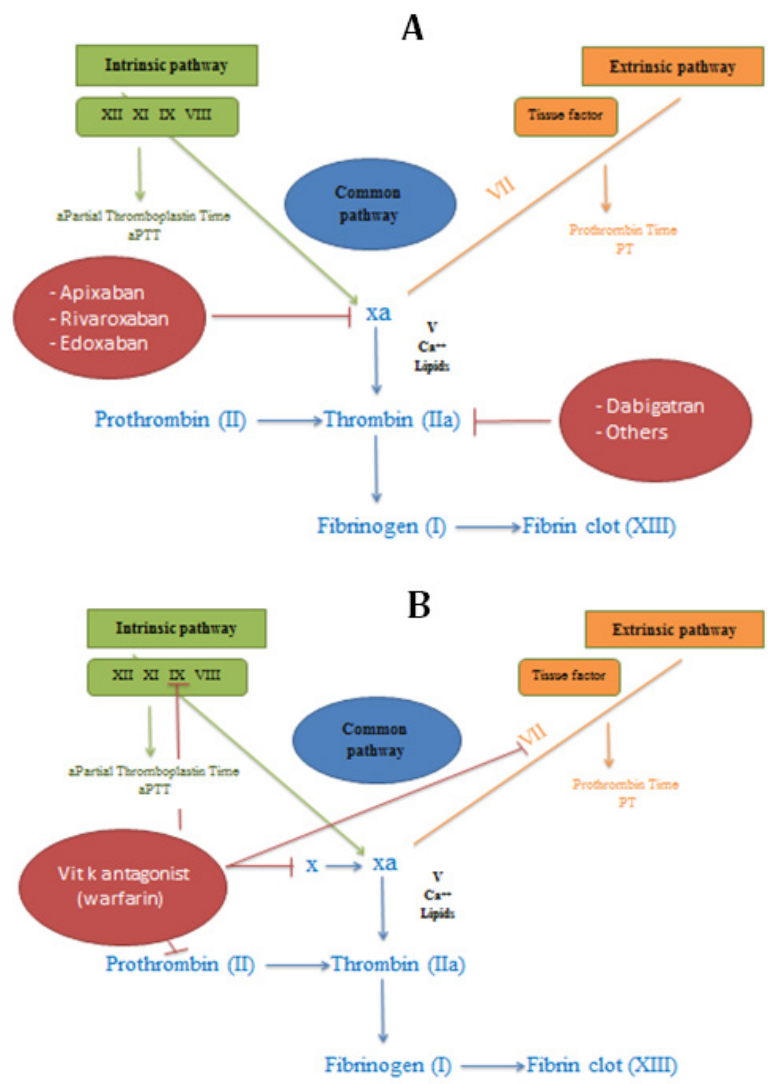

Figure I Sites of action of DOACs.

A. Apixaban and Rivarixaban target Xa whereas Dabigatran targets thrombin (lla)

B. Warfarin targets multiple factors (factors II, VII, IX, and X). 
Table I The table shows the comparison between warfarin and DOACs on their targets, dosing rate, bioavailabilty, half-life, Cmax, vitamin $\mathrm{k}$ dependent, laboratory monitoring and renal excretion

\begin{tabular}{|c|c|c|c|c|c|}
\hline & Warfarin & Apixaban & Dabigatran & Rivaroxaban & Edoxaban \\
\hline Licenced condition & AF,VTE, valvular heart disease & AF,VTE & $\mathrm{AF}$ & AF,VTE & Approval pending \\
\hline Target & Factors II, VII, IX, and X & Factor $\mathrm{Xa}$ & Activated factor (Ila) thrombin & Factor $\mathrm{Xa}$ & Factor Xa \\
\hline Dosing rate & Daily & Twice daily & Twice daily & Daily & Daily \\
\hline Bioavailability & $100 \%$ & $50 \%$ & $6.50 \%$ & $66 \%$ & $40 \%-59 \%$ \\
\hline Half-life (hours) & 40 & 12 & $12-14$ & $11-13$ & $5.8-10.7$ \\
\hline Cmax (hours) & 02-Jun & $3-4$ & $0.5-2.0$ & $2-4$ & OI-Feb \\
\hline Vitamin $\mathrm{K}$ dependent & Yes & No & No & No & No \\
\hline $\begin{array}{l}\text { Laboratory } \\
\text { monitoring }\end{array}$ & Yes & No & No & No & No \\
\hline Renal excretion \% & 0 & 27 & 85 & 36 & 40 \\
\hline
\end{tabular}

\section{Characteristics of oral anticoagulants}

\section{Direct oral anticoagulants (DOAC)}

The first approved DOAC was Dabigatran that approved by the EU in 2008, in 2010 by the Food and Drug Administration (FDA) ${ }^{6}$ and Australia in 2012 by PBS. ${ }^{3}$ It prevents the conversion of fibrinogen to fibrin by direct inhibition of thrombin (factor IIa) and thus manages the formation of the clot. Dabigatran has a role in reducing the risk of systemic embolism and stroke in non-valvular atrial fibrillation patients. ${ }^{7}$ This drug does not interact with food so it can be given with or without food and its absorption and bioconversion occur in hepatocytes, hepatic portal vein and the intestinal cells. ${ }^{7}$

The second approved DOAC in the USA was Rivaroxaban. ${ }^{8}$ This drug targets the common pathway factor $(\mathrm{Xa})$ which in turn prevents activation of the thrombin and thereby blocks clot formation. It should be given within 2 hours of eating ${ }^{9}$ and its metabolism happens in the liver. The pharmacokinetics (PK) and pharmacodynamic (PD) properties of Rivaroxaban show no difference in regard to race and sex. ${ }^{10}$ Interestingly, the mild hepatic disease Child-Pugh Class A does not cause any clinically significant changes in the PK and PD of Rivaroxaban even though the hepatic and renal failure insufficiency affects the PK and PD properties of the drug. ${ }^{11}$

The third approved DOAC by FDA and European medicine agency $^{12}$ was Apixaban. This inhibits the same target of Rivaroxban, factor Xa. It leads to the same activity of Rivaroxaban by preventing the conversion of fibrinogen to fibrin through blocking the formation of thrombin from prothrombin. It has no food interaction and it is metabolized in the CYP-dependent isozyme pathway (CYP3A4) in the liver. ${ }^{13}$

The fourth DOAC submitted by the Daiichi Sankyo Company, in 2014 was Edoxaban. ${ }^{14}$ Clinical studies showed that this drug will likely be more efficient to treat some thrombotic disorders. ${ }^{15}$ Edoxaban inhibits factor $\mathrm{Xa}$ and leads to block the formation of fibrin clot. It does not interact with food and is absorbed rapidly. The highest concentration of Edoxaban is metabolized via hydrolysis and other minor metabolites are absorbed through cytochrome P450 3A enzymes. ${ }^{16}$ Approximately $40 \%$ of Edoxaban can be detected in the urine and $60 \%$ in the faeces. ${ }^{16}$

\section{Direct oral anticoagulants (DOACs) vs Warfarin}

Dabigatran reduces the risk of intracranial hemorrhage, ischemic stroke and mortality compared to Warfarin. However, some studies showed that it increases the risk of gastrointestinal bleeding in nonvalvular atrial fibrillation elderly patients. ${ }^{17,18}$ According to the RECOVER trial, Dabigatran users had lesser major bleeding episodes than the Warfarin group indicating an advantage of Dabigatran. ${ }^{19}$ Moreover, RE-COVER trial II revealed that the risk of any bleeding is considerably lower with Dabigatran compared to Warfarin. ${ }^{20}$ Apixaban also displays advantages over Warfarin in preventing stroke and systemic embolism in atrial fibrillation patients. In addition, the rate of mortality is lower with group of Apixaban compared to Warfarin users. ${ }^{12}$ According to the ENGAGE AF-TIMI $48^{21}$ and Hokusai-VTE ${ }^{22}$ trials, Edoxaban showed promising results over Warfarin in major and non-major bleeding.

\section{Limitations to direct oral anticoagulants}

There are contraindications or limitations of these drugs in some circumstances. These drugs are not approved to be used for newborns, children and during pregnancy. ${ }^{23,24}$ In addition, DOACs increase the risk of bleeding and thromboembolism in patients with mechanical mitral valves. ${ }^{25}$ They are also not used with anti-phospholipid syndrome patients as well as malignant disease patients as the drugs increase the risk of thrombophilic conditions. ${ }^{26}$ Moreover, these drugs are not suitable or should be used with caution for people who are suffering from kidney or liver disease. ${ }^{27}$ Approximately $85 \%$ of Dabigatran is eliminated through the kidneys so, it is not recommended for severe renal failure patients. ${ }^{28}$ While Apixaban and Rivaroxaban have lower elimination by kidneys, they must be used with care and renal function should be considered before using the drugs. Note, Warfarin is not eliminated by the kidneys.

\section{Reversal of DOACs}

Several antidotes have been developed to reverse the anticoagulation activity of DOACs. Idarucizumab (Praxbind), a monoclonal antibody, has been approved by the Therapeutic Good Administration (TGA) to reverse the anticoagulant activity of Dabigatran. ${ }^{29}$ Idarucizumab specifically binds to Dabigatran, reversing its anticoagulant effect and is now approved by the TGA and available in Australia. Idarucizumab 
exhibited complete reversal of Dabigatran within 4hours in $89 \%$ of 123 enrolees according to an ongoing trial of patients with uncontrolled bleeding or who require urgent procedures. ${ }^{30-33} \mathrm{~A} 5 \mathrm{~g}$ of Idarucizumab is the recommended dose and administered via bolus injection or intravenous infusion as two consecutive $2.5 \mathrm{~g}$ doses..$^{34}$ Dabigatran can also be reversed with hemodialysis in the case of Dabigatran-related bleeding. ${ }^{30-33}$

Andexanet alfa which is a recombinant protein developed by Portola Pharmaceuticals ${ }^{35}$ that binds to factor Xa inhibitors reversing their anticoagulant action. It has been shown to successfully and significantly reverse the anticoagulation activity of Rivaroxaban (xarelto) as well as Apixaban (eliquis); ${ }^{35}$ however, this drug has not yet been approved by the FDA. The recommended doses of Andexanet alfa to reverse Rivaroxaban at the highest approved dose $(20 \mathrm{mg}$ once a day) are varied; it can be administered either as an $800 \mathrm{mg}$ intravenous bolus (part 1) or as an $800 \mathrm{mg}$ intravenous bolus followed by $8 \mathrm{mg}$ per minute for 120 minutes (part 2). ${ }^{36}$ Moreover, a $400 \mathrm{mg}$ intravenous bolus (part 1) or 400mg intravenous bolus followed by $4 \mathrm{mg}$ per minute for 120minutes (part 2) are the recommended doses to reverse $5 \mathrm{mg}$ of apixaban orally twice daily. ${ }^{36}$

Edoxaban can be reversed potentially with recombinant factor VIIa (rFVIIa), Feiba, and PPSB-HT. Critical study showed that Edoxaban is reversed significantly by rFVIIa ( 1 and $3 \mathrm{mg} / \mathrm{kg}$, i.v.) and Feiba $(100 \mathrm{U} / \mathrm{kg}$, i.v.) for $(1 \mathrm{mg} / \mathrm{kg} / \mathrm{h})$-induced prolongation of bleeding time in rats. ${ }^{37}$ Non-specific clotting factor products such as prothrombin complex concentrate (PCC) (PPSB-HT), activated prothrombin complex concentrate (aPCC) (Feiba) or recombinant factor VIIa (rFVIIa) can also be considered to reverse DOACs. ${ }^{30-33}$ However, their efficacy is still unproven and they require cautious administering as these pro-coagulant clotting factors particularly rFVIIa, can result in thrombosis.

\section{Future direction of direct oral anticoagulants}

The specific antidotes for the DOACs are still not fully approved which make their reversal in patients with life-threatening bleeding or those who require urgent surgery complicated. However, the outcome of DOACs is better than warfarin in major bleeds i.e. less intracranial bleeding was shown with all three DOACs compared to Warfarin. ${ }^{38,39}$

Although the laboratory monitoring of DOACs is not needed, it can required in some circumstances. The DOACs have variable effects on the prothrombin time (PT) and activated atrial thromboplastin time $(\mathrm{aPTT})^{40}$ which make their assessment difficult. However, several drug-specific calibrators have been developed to measure the DOACs in plasma. The chromogenic anti-factor Xa assays have been developed to measure the effect of Rivaroxaban and Apixaban on FXa activity whereas the Hemoclot dilute thrombin time assay and chromogenic ecarin assay can be used to assess the activity of Dabigatran. ${ }^{41}$ The availability of drug-specific calibrators as well as development of antidotes might simplify the reversal of DOACs. Ongoing study on efficacy and safety of DOACs reversal will provide physicians a key to manage uncontrolled bleeding due to DOACs.

\section{Acknowledgements}

None.

\section{Conflict of interest}

The author declares no conflict of interest

\section{References}

1. Alex Gallus. New oral anticoagulants-clinical applications. Aust Prescr. 2010;33:42-47.

2. Brieger D. Anticoagulation: a GP primer on the new oral anticoagulants. Aust Fam Physician. 2014;43(5):254-259.

3. Chin PK, Doogue MP. Long-term prescribing of new oral anticoagulants. Aust Prescr. 2016;39(6):200-204.

4. Hinojar R, Jiménez-Natcher JJ, Fernández-Golfín C, et al. New oral anicoagulants: a practical guide for physicians. European Heart JournalCardiovascular Pharmacotherapy. 2015;1(2):134-145.

5. Pratt NL, Ramsay EN, Caughey GE, et al. Uptake of novel oral anticoagulants in Australia. Med J Aust. 2016;204(3):104-105.

6. Connolly SJ, Ezekowitz MD, Yusuf S, et al. Dabigatran versus warfarin in patients with atrial fibrillation. N Engl J Med. 2009;361(12):11391151.

7. Da Silva RM. Novel oral anticoagulants in non-valvular atrial fibrillation. Cardiovasc Hematol Agents Med Chem. 2014;12(1):3-8.

8. Little JW. New oral anticoagulants: will they replace warfarin? Oral Surg Oral Med Oral Pathol Oral Radio. 2012;113(5):575-580.

9. Eriksson BI, Borris LC, Dahl OE, et al. ODIXa-HIP Study Investigators A once-daily, oral, direct Factor Xa inhibitor, rivaroxaban (BAY 597939), for thromboprophylaxis after total hip replacement. Circulation. 2006;114(22):2374-2381.

10. Turpie AG, Fisher WD, Bauer KA, et al. BAY 59-7939: an oral, direct factor $\mathrm{Xa}$ inhibitor for the prevention of venous thromboembolism in patients after total knee replacement. A phase II dose-ranging study. $J$ Thromb Haemost. 2005;3(11):2479-2486.

11. Kubitza D, Roth A, Becka M, et al. Effect of hepatic impairment on the pharmacokinetics and pharmacodynamics of a single dose of rivaroxaban, an oral, direct Factor Xa inhibitor. Br J Clin Pharmacol. 2013;76(1):89-98.

12. Granger CB, Alexander JH, McMurray JJ, et al. Apixaban versus warfarin in patients with atrial fibrillation. $N$ Engl J Med. 2011;365(11):981-992.

13. Weinz C, Radke M, Sshmreer R. In vitro metabolisem of BAY 597939 and oral, direct factor Xa inhibitor. Drug Metab Rev. 2004;36(Suppl 1):98.

14. Hughes GJ, Hilas O. Edoxaban: an investigational factor Xa inhibitor. $P$ T. 2014;39(10):686-715.

15. Alyssa Dargento. Daiichi Sankyo submits Savaysa (edoxaban) tablets new drug application to the US FDA for once-daily use for stroke risk reduction in atrial fibrillation and for the treatment and prevention of recurrence of venous thromboembolism. Japan: Daiichi Sankyo Company; 2014

16. Bathala MS, Masumoto $\mathrm{H}$, Oguma $\mathrm{T}$, et al. Pharmacokinetics, biotransformation, and mass balance of edoxaban, a selective, direct factor Xa inhibitor, in humans. Drug Metab Dispos. 2012;40(12):2250 2255 .

17. Holster IL, Valkhoff VE, Kuipers EJ, et al. New oral anticoagulants increase risk for gastrointestinal bleeding: a systematic review and metaanalysis. Gastroenterology. 2013;145(1):105-112.

18. Graham DJ, Reichman ME, Wernecke M, et al. Cardiovascular, bleeding, and mortality risk in elderly Medicare patients treated with dabigatran or warfarin for nonvalvular atrial fibrillation. Circulation. 2015;131(2):157-164. 
19. Schulman S, Kearon C, Kakkar AK, et al. Dabigatran versus warfarin in the treatment of acute venous thromboembolism. $N$ Engl J Med. 2009;361(24):2342-2352.

20. Schulman S, Kakkar AK, Goldhaber SZ, et al. Treatment of acute venous thromboembolism with dabigatran or warfarin and pooled analysis Circulation. 2014;129(7):764-772.

21. Giugliano RP, Ruff CT, Braunwald E, et al. Edoxaban versus warfarin in patients with atrial fibrillation. $N$ Engl J Med. 2013;369(22):2093-2104.

22. Büller HR, Décousus H, Grosso MA, et al. Edoxaban versus warfarin for the treatment of symptomatic venous thromboembolism. $N$ Engl J Med. 2013;369(15):1406-1415.

23. Mekaj YH, Mekaj AY, Duci SB, et al. New oral anticoagulants: their advantages and disadvantages compared with vitamin $\mathrm{K}$ antagonists in the prevention and treatment of patients with thromboembolic events. Ther Clin Risk Manag. 2015;11:967-977.

24. Erik Walter Holy, Hans-Jürg Beer. Update on the status of new ora anticoagulants for stroke prevention in patients with atrial fibrillation. Cardiovascular Medicine. 2013;16(04):103-114.

25. Eikelboom JW, Connolly SJ, Brueckmann M, et al. Dabigatran versus warfarin in patients with mechanical heart valves. $N$ Engl $\mathrm{J}$ Med. 2013;369(13):1206-1214

26. Hoffman R, Brenner B. The promise of novel direct oral anticoagulants Best Pract Res Clin Haematol. 2012;25(3):351-360.

27. Douxfils J, Tamigniau A, Chatelain B, et al. Measurement of non-VKA oral anticoagulants versus classic ones: the appropriate use of hemostasis assays. Thromb J. 2014;12:24.

28. Wang Y, Bajorek B. New oral anticoagulants in practice: pharmacological practical considerations. Am J Cardiovasc Drugs. 2014;14(3):175-189.

29. Kafke W, Kraft P. Intravenous thrombolysis after reversal of dabigatran by idarucizumab: a case report. Case Rep Neurol. 2016;8(2):140-144.

30. Luca Masotti, Giancarlo Landini, et al.The practical management of bleedings during treatment with direct oral anticoagulants: the emergency reversal therapy. Italian Journal of Medicine. 2013;7(8S):48-58.
31. Siegal DM. Managing target-specific oral anticoagulant associated bleeding including an update on pharmacological reversal agents. $J$ Thromb Thrombolysis. 2015;39(3):395-402.

32. Heidbuchel H, Verhamme P, Alings M, et al. European heart rhythm association practical guide on the use of new oral anticoagulants in patients with non-valvular atrial fibrillation. Europace. 2013;15(5):625651.

33. John Camm, Jeffrey I Weitz. The changing landscape in oral anticoagulation-the last pieces of the puzzle. EMJ Cardiol. 2013;1:5271.

34. Steve Chaplin. Idarucizumab to reverse effects of anticoagulant dabigatran. Prescriber. 2016;27(5):40-41.

35. Dolgin E. Antidotes edge closer to reversing effects of new blood thinners. Nat Med. 2013;19(3):251.

36. Deborah M Siegal, John T Curnutte, Stuart J Connolly, et al. Andexane alfa for the reversal of factor Xa inhibitor activity. The New England journal of medicine. 2015;373(25):2413-2424.

37. Fukuda T, Honda Y, Kamisato C, et al. Reversal of anticoagulant effects of edoxaban, an oral, direct factor Xa inhibitor, with haemostatic agents. Thromb Haemost. 2012;107(2):253-259.

38. Hart RG, Diener HC, Yang S, et al. Intracranial hemorrhage in atria fibrillation patients during anticoagulation with warfarin or dabigatran: the RE-LY trial. Stroke. 2012;43(6):1511-1517.

39. Majeed A, Hwang HG, Connolly SJ, et al. Management and outcomes of major bleeding during treatment with dabigatran or warfarin. Circulation. 2013;128(21):2325-2332.

40. Garcia D, Barrett YC, Ramacciotti E, et al. Laboratory assessment of the anticoagulant effects of the next generation of oral anticoagulants. $J$ Thromb Haemost. 2013;11(2):245-252.

41. Karli B, Bartel B, Pavelko R. Reversal strategies for intracrania hemorrhages in patients taking oral factor Xa inhibitors. Hosp Pharm. 2015;50(7):569-577. 